\title{
Interdecadal Temperature Variations in the North Pacific Central Mode Water Simulated by an OGCM
}

\author{
Shigeki Hosoda ${ }^{1 *}$, Shang-Ping Xie ${ }^{2}$, Kensuke Takeuchi $^{3}$ and Masami Nonaka ${ }^{4}$ \\ ${ }^{1}$ Japan Marine Science and Technology Center, Natsushima-cho, Yokosuka 237-0061, Japan \\ ${ }^{2}$ International Pacific Research Center and Department of Meteorology, School of Ocean and \\ Earth Science and Technology, University of Hawaii, Honolulu, HI 96822, U.S.A. \\ ${ }^{3}$ Frontier Observational Research System for Global Change, \\ Natsushima-cho, Yokosuka 237-0061, Japan \\ ${ }^{4}$ International Pacific Research Center, School of Ocean and Earth Science and Technology, \\ University of Hawaii, Honolulu, HI 96822, U.S.A.; and \\ Frontier Research System for Global Change, Yokohama 236-0001, Japan
}

(Received 14 August 2003; in revised form 28 October 2003; accepted 18 November 2003)

The North Pacific Central Mode Water (CMW) is a water mass that forms in the Kuroshio-Oyashio Extension (KOE) region with characteristic low potential vorticity. Recent studies have suggested that the CMW, as low potential vorticity water, plays an important role in the adjustment of the subtropical gyre and subsurface variability on decadal to interdecadal timescales. We have forced a realistic ocean general circulation model (OGCM) with observed wind stress and sea surface temperature (SST) forcing to investigate the decadal variations of the CMW. Associated with the large atmospheric changes after the mid-1970s climate regime shift, the upper thermocline experiences a cooling as negative SST anomalies in the central North Pacific are subducted and advected southward. In addition to this thermodynamic response, the CMW's path shifts anomalously eastward in response to anomalous Ekman pumping. This eastward shift of the core of the CMW produces a lowering of the isotherms, and a consequent warming, on the path of the CMW core. This warming partially counteracts the cooling associated with subducted surface anomalies, and it may be responsible for the reduced temperature variations at the climatological position of the CMW when both anomalous wind and heat fluxes are given. Lateral induction across the sloping bottom of the winter mixed layer in the KOE is critical to the formation of the low potential vorticity CMW. Coarse resolution models, which are widely used in climate modeling, underestimate the horizontal gradient of the mixed layer depth and form only a weak CMW or none at all. We have conducted a coarse resolution experiment with the same OGCM, showing that the subsurface response is much reduced. In particular, there is no dynamic warming in the CMW and the thermodynamic response to the SST cooling dominates. The resultant total response differs substantially from that in the finer resolution run where a strong CMW forms. This sensitivity to the model resolution corroborates the important dynamical role that the CMW may play with its distinctive low potential vorticity character and calls for its improved simulation.
Keywords:

- Decadal variabil-

ity,

- OGCM,

- Central Mode

Water,

- simulation.

\section{Introduction}

Pronounced decadal/interdecadal climate variability has been observed in sea surface temperature (SST), wind and other ocean-atmospheric fields over the North Pa-

\footnotetext{
* Corresponding author. E-mail: hosodas@jamstec.go.jp

Copyright $@$ The Oceanographic Society of Japan.
}

cific (Nitta and Yamada, 1989; Tanimoto et al., 1993; among others). Such climate variations influence the weather conditions of the countries surrounding the North Pacific (e.g. Minobe, 1997) as well as fishery resources (Mantua et al., 1997; Yasuda et al., 1999). Thus, it is both scientifically and societally important to study the origin of this decadal climate variability. The present study is an effort to understand the mechanisms underlying 
decadal/interdecadal subsurface variability in the North Pacific.

Wind-induced changes in turbulence heat flux at the sea surface and in Ekman advection are important for decadal SST anomalies over the North Pacific (e.g. Cayan, 1992). With slow adjustment timescales, ocean dynamics are an important mechanism for decadal SST variability in certain regions. For example, in the KuroshioOyashio Extension (KOE) region east of Japan, ocean dynamics contribute significantly to decadal SST variability there (Latif and Barnett, 1994; Qiu, 2000; Tomita et al., 2002) and long-term variability of North Pacific Subtropical Mode Water (Yasuda and Kitamura, 2003). In particular, Xie et al. (2000) forced an ocean general circulation model (OGCM) with observed interannual variations in wind stress but restored SST back to the observed climatology. In such a model without anomalous atmospheric thermal forcing, they found large SST variability in the KOE and equatorial Pacific and suggested that they are the windows where subsurface thermocline variability can significantly impact SST. In the KOE window, remotely forced baroclinic Rossby waves (Schneider and Miller, 2001) and the meridional shift of the gyre boundary (Seager et al., 2001) are the main mechanisms by which subsurface variability affects SST.

\subsection{Rossby wave adjustment}

With slow adjustment timescales, the subsurface thermocline responds very effectively to decadal/ interdecadal changes at the sea surface by several mechanisms. First, anomalous Ekman pumping velocity associated with a change in wind stress distribution excites Rossby waves of the first baroclinic mode that propagate westward. Subsurface temperature anomalies due to this mechanism tend to intensify westward (Miller et al., 1998). Deser et al. (1999) provide observational evidence for such a westward intensified adjustment to the climate regime shift that occurred in the mid-1970s. When such remotely forced Rossby waves propagate into the KOE region where the winter mixed layer is deep, they leave a strong SST signature (Xie et al., 2000; Schneider et al., 2002).

Changes in surface wind also forces local SST anomalies by means of surface turbulence heat flux and Ekman advection. These SST anomalies can be subducted into the main thermocline and advected southward by the subtropical gyre (Gu and Philander, 1997; Schneider et al., 1999; Nonaka et al., 2000). Such subducted temperature anomalies from the sea surface are observed in the central subtropical gyre (Deser et al., 1996; Yasuda and Hanawa, 1997; Zhang et al., 1998). Temperature anomalies thus generated roughly follow the streamlines on isopycnals and can also be viewed as Rossby waves of higher baroclinic modes (Liu, 1999; Nonaka and Xie, 2000).

\subsection{Mode water adjustment}

In addition to the above adjustment via Rossby waves of various vertical modes, recent theoretical (Kubokawa and Xie, 2002) and modeling (Inui et al., 1999; Xie et al., 2000) studies indicate a new dynamical mechanism for subsurface temperature changes that involves the socalled North Pacific Central Mode Water (CMW). The CMW is a water mass with low potential vorticity (PV) and low vertical temperature gradient that extends from $30^{\circ}$ to $40^{\circ} \mathrm{N}$ and from $170^{\circ} \mathrm{E}$ to $150^{\circ} \mathrm{W}$ and is formed in the deep winter mixed layer in the KOE region (Nakamura, 1996; Suga et al., 1997). Forcing a realistic North Pacific OGCM with observed wind stress, Xie et al. (2000) report a temperature variance maximum collocated with the model CMW. In response to changes in the formation region (Inui et al., 1999) and anomalous gyre circulation (Kubokawa and Xie, 2002), the CMW changes its path and this shift in the location of this thick layer of the vertically uniform water mass leads to large subsurface temperature anomalies along its path. This CMW-path mechanism has yet to be confirmed by observations, which so far suffer from a lack of long-term subsurface measurements with adequate spatial and temporal resolution. In an analysis of available subsurface observations, Yasuda and Hanawa (1997) find that the CMW's core temperature decreased after the mid-1970s climate regime shift.

With its phase propagation and amplitude amplification toward the west, the first baroclinic-mode Rossby wave mechanism is relatively easy to identify in observations and models. It is difficult to distinguish a subducted SST anomaly from the subsurface anomaly due to the shift in the CMW path as they both follow the characteristics/streamlines on isopycnals. Previous studies have examined these two mechanisms separately, by turning off either anomalous wind stress (Nonaka et al., 2000) or anomalous atmospheric thermal (Xie et al., 2000) forcing, but their relative importance and possible interaction remain unclear.

The present study extends the previous work by assessing the relative importance of these two mechanisms that give rise to anomalies along subduction characteristics. We have carried out a series of sensitivity experiments that remove either anomalous wind or thermal forcing at the sea surface and compared the results with a control run with both wind and thermal forcing included. Attempts are also made to compare with available observations where possible.

\subsection{Resolution issue}

While many earlier OGCM simulations were carried 
Table 1. Model parameters and surface boundary conditions.

\begin{tabular}{|c|c|c|c|c|}
\hline Exp. & $\begin{array}{l}\text { Horizontal grid } \\
\text { (degree) }\end{array}$ & $\begin{array}{l}\text { Horizontal viscosity } \\
\text { in } 10^{9} \mathrm{~cm}^{2} \mathrm{~s}^{-1}\end{array}$ & $\begin{array}{l}\text { Isopycnal tracer diffusion } \\
\text { in } 10^{8} \mathrm{~cm}^{2} \mathrm{~s}^{-1}\end{array}$ & Surface boundary condition* \\
\hline FR & $1 \times 1$ & 0.1 & 0.2 & WT, W, T \\
\hline $\mathrm{CR}$ & $3 \times 3$ & 1.0 & 2.0 & WT \\
\hline LM & $1 \times 1$ & 1.0 & 2.0 & WT \\
\hline
\end{tabular}

*The characters "WT", "W" and "T" are noted in Section 2.

out with rather coarse resolutions $(3 \times 3$ degrees $)$ due to limited computing resources, the dependence of the results on horizontal resolution has not been systematically investigated. Subsurface variability due to the subduction of SST anomalies does not appear to be very sensitive to the choice of horizontal resolution. Qualitatively, results obtained with resolutions close to 3 degrees (about 2.8 degrees around Mid-latitude in Schneider et al., 1999; 4 degrees for interior ocean in Miller et al., 1998) agree relatively well with results obtained with higher resolutions close to 1 degree (Nonaka et al., 2000). There are reasons to believe that subsurface anomalies associated with changes in the path of the CMW are significantly reduced in coarse resolution OGCMs used in several previous studies. Using the ventilated thermocline theory, Kubokawa (1999) shows that the strong gradient in winter mixed layer depth (MLD) is key to the mode water formation with a distinctive PV minimum on an isopycnal surface. Such a low-PV water forms at the crossing point between the outcropping line and a so-called MLD front where the MLD increases rapidly from values typical of an interior subtropical gyre (less than $100 \mathrm{~m}$ ) to more than $200 \mathrm{~m}$ near the KOE. This mode-water formation mechanism is confirmed in both idealized (Kubokawa and Inui, 1999) and realistic (Xie et al., 2000) OGCMs. In a ventilated thermocline model, a weakened MLD front reduces the effect of the CMW-path mechanism on subsurface temperature (Kubokawa and Xie, 2002). Insufficient horizontal resolution inevitably weakens the MLD front that is observed in the western North Pacific, leading to an unrealistic simulation of mode waters.

Another purpose of this study was to investigate the sensitivity of simulated subsurface variability to the representation of the mode water. We have demonstrated this sensitivity by contrasting the results from the control run with simulations under reduced horizontal resolutions and/or increased horizontal diffusion. Such a knowledge of resolution sensitivity will help better interpret OGCM simulations at various horizontal resolutions.

The rest of this paper is organized as follows. Section 2 describes the model, data and experiment designs. Section 3 examines the temperature variations in the CMW. Section 4 investigates sensitivity to model hori- zontal resolution. Section 5 offers further discussions and a summary.

\section{Experiments}

\subsection{Model}

We used the GFDL modular ocean model, MOM 1.1 (Pacanowski et al., 1991). This model solves the primitive equations in spherical coordinates, under the Boussinesq, rigid-lid and hydrostatic approximations. The model covers the North Pacific from $65^{\circ} \mathrm{N}$ to $15^{\circ} \mathrm{S}$, with realistic coastal and bottom topography. It employs the nonslip lateral boundary condition and requires the fluxes of mass, temperature and salinity to vanish at all boundaries except the sea surface. Near the poleward boundaries, temperature and salinity are restored to the WOA94 monthly climatology data (Levitus and Boyer, 1994; Levitus et al., 1994) at all vertical levels. The restoring time constant is 2 days at north and south walls, decreasing exponentially to infinity toward the interior within 8 degrees from each wall. Unless stated otherwise, the horizontal resolution is 1 degree. There are 32 vertical levels with a $10 \mathrm{~m}$ resolution near the sea surface, and the mixed layer is formed by vertical convection. The vertical viscosity is $5.0 \mathrm{~cm}^{2} \mathrm{~s}^{-1}$, and the standard value for the horizontal viscosity is $1.0 \times 10^{8} \mathrm{~cm}^{2} \mathrm{~s}^{-1}$. Temperature and salinity are mixed both along and across isopycnal surfaces (Cox, 1987), with a diapycnal mixing coefficient of 0.3 $\mathrm{cm}^{2} \mathrm{~s}^{-1}$ and isopycnal diffusivity of $2.0 \times 10^{7} \mathrm{~cm}^{2} \mathrm{~s}^{-1}$. Horizontal resolution and horizontal and isopycnal mixing coefficients were modified in some experiments, to be presented in Section 4. Table 1 summarizes the model parameters.

\subsection{Experiment designs}

The model is forced at the sea surface with monthly wind stress derived from the National Centers for Environmental Prediction/National Center for Atmospheric Research (NCEP/NCAR) reanalysis (Kalnay et al., 1996). The model SST is restored toward the monthly Reynolds and Smith (1994) analysis of ship and satellite measurements and sea surface salinity (SSS) toward the WOA94 monthly climatology. At this time, observed fresh water 

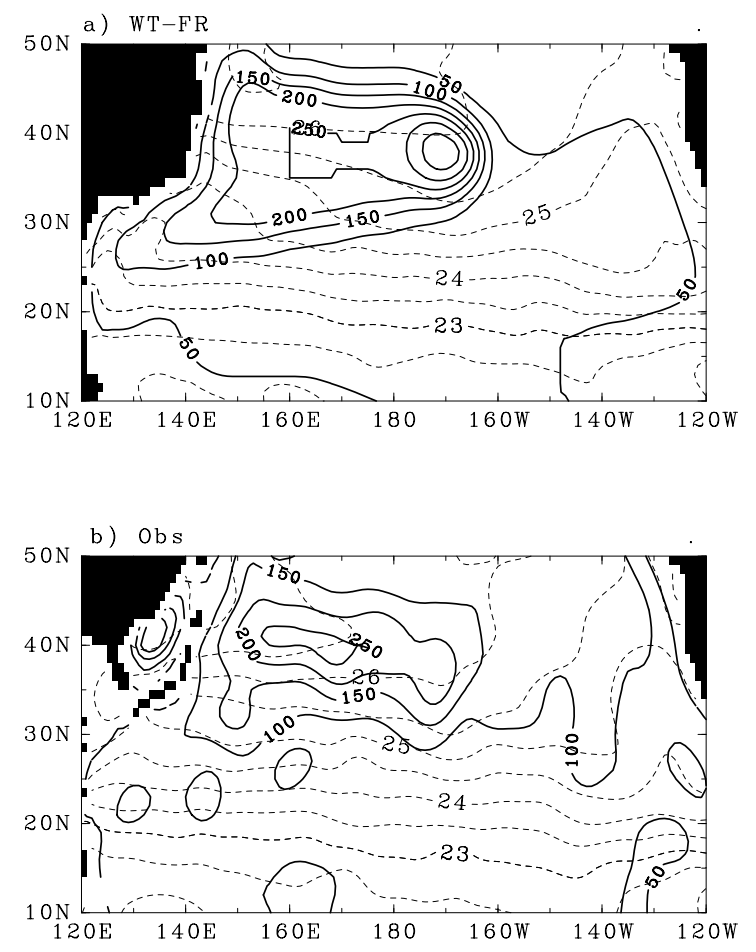

Fig. 1. March mixed layer depth (thick solid in $\mathrm{m}$ ) with surface density fields (thin dashed; in $\sigma_{\theta}$ ) in (a) the WT-FR run (averaging for 40 years) and (b) the observed climatology.

fluxes are available only for two recent decades and their accuracy is still under investigation. Thus, it is difficult to include fresh water fluxes in the model and to compare with observed salinity distribution. In this paper, for simplicity, we exclude the effect of fresh water flux variation. The restoring time constant is 14 days for the top layer of the model $(10 \mathrm{~m})$. The model is first spun up for 40 years under the climatological surface wind and SST forcing from a resting state with the WOA94 climatological temperature and salinity fields as the initial conditions. At the end of the spin-up, the model reaches a quasi-steady state and repeats a regular seasonal cycle. The surface forcing is then gradually changed over a 10-year period from the climatology to the 1958 fields to reduce the shock from this forcing change. Thereafter, we apply the observed monthly history of the wind and SST forcing based on NCEP/NCAR reanalysis and the Reynolds and Smith analysis for the 40-year period from January 1958 to December 1997. Because of lack of adequate SSS datasets, the model SSS is still restored toward the WOA94 monthly climatology. We call this experiment under the full wind and SST forcing "WT" runs in each resolution. We also carried out the following additional experiments. In run "W", we applied the interannual wind forcing but restored SST to its monthly
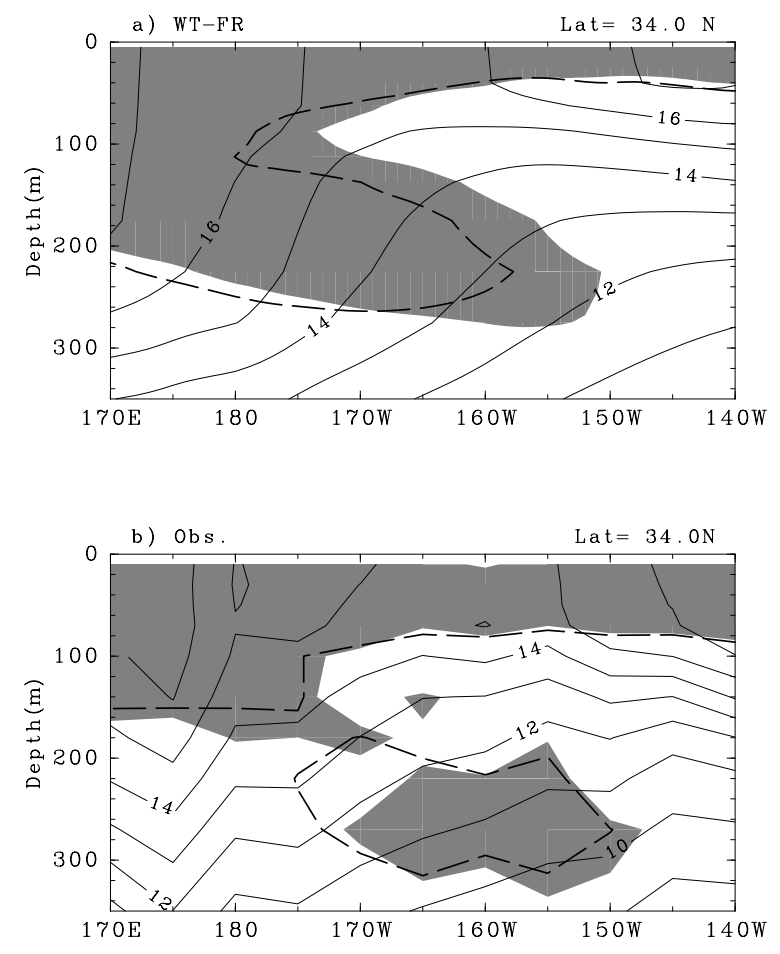

Fig. 2. 40-year mean March temperature as a function of longitude and depth at $34^{\circ} \mathrm{N}$ in (a) the WT-FR run and (b) observations. The CMW before and after the 1970 s climate regime shift is marked in dashed line and shade, respectively. The CMW is defined as where PV is below $1.0 \times$ $10^{-10} \mathrm{~m}^{2} \mathrm{~s}^{-1}$ in (a) and $(-(\partial T) /(\partial z))<0.015^{\circ} \mathrm{C} \mathrm{m}^{-1}$ in (b).

climatology to isolate the effects of wind stress forcing. In run "T", on the other hand, we restored SST to the observed values for 1958-97 but held the wind stress forcing to its climatology to isolate the effects of the SST forcing (see Table 1).

In parallel with the above interannual runs, we also continued the spin-up run for another 50 years with the climatological wind and SST forcing. This served as a control with finer $(1 \times 1$ degree $)$ resolution (the FR run) and the deviations from this control, defined as interannual anomalies, are analyzed in this paper.

\subsection{Comparison with observations}

Figure 1 compares the sea surface density and MLD in March between the OGCM solution and the WOA94 observations. The model simulates the salient features of the observed MLD distribution, including a depth maximum along $40^{\circ} \mathrm{N}$. MLD is generally less than $100 \mathrm{~m}$ over most of the subtropical gyre except in the KOE, where it is $200 \mathrm{~m}$ or deeper. Differences in the details are also apparent. For example, the local maximum with MLD exceeding $350 \mathrm{~m}$ at $170^{\circ} \mathrm{W}, 38^{\circ} \mathrm{N}$ is absent in observations. The horizontal gradient of the model MLD distri- 


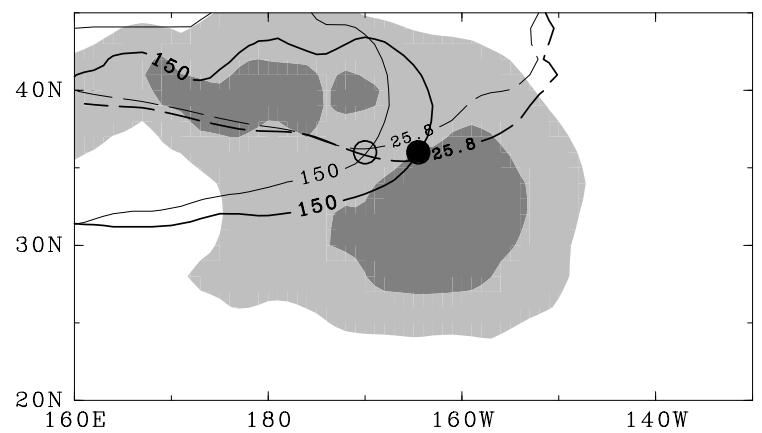

Fig. 3. Decadal SST difference between 1967-76 and 1977-86 with light (dark) shade $<-0.4^{\circ} \mathrm{C}\left(-0.8^{\circ} \mathrm{C}\right)$. The $25.8 \sigma_{\theta}$ surface-density and $150 \mathrm{~m}$ MLD contours that mark the outcrop line and the MLD front, respectively, before (thin) and after (thick) the climate regime shift. The CMW forms at the open (filled) circle before (after) the shift where the outcrop line and MLD front cross.

bution is generally stronger than the WOA94 climatology, a discrepancy resulting partially from heavy smoothing in WOA94 grid data. The model surface density field agrees with observations over most of the model except in the Kuroshio and KOE because of the model's inability. The MLD gradient is a key element to the formation of mode waters characterized by low PVs. Kubokawa (1999) and Xie et al. (2000) show that low PV water forms in a region where a surface density isoline crosses the MLD front. This warm/light bias of model surface temperature/density in the KOE east of Japan leads to a warm/ light bias in the model mode waters. Thus we use $25.8 \sigma_{\theta}$ as the core density for the model CMW, while the observed CMW has a typical density of $26.2 \sigma_{\theta}$ (Suga et al., 1997).

We compared the model solutions with a subsurface temperature dataset that White (1995) compiled based on expandable bathythermometer (XBT) measurements for 1955-98. The dataset is on a $2^{\circ}$ latitude $\times 5^{\circ}$ longitude grid, with 11 vertical levels from the sea surface to 400 $\mathrm{m}$. With many shipping lines, the North Pacific is among the regions best sampled by the XBTs. We feel that this dataset offers useful information on the slow decadal/ interdecadal variations in the North Pacific, as demonstrated in previous studies (Schneider et al., 1999; Xie et al., 2000).

In analyzing the XBT data, we define the CMW as the region where $(-(\partial T) /(\partial z))<0.015^{\circ} \mathrm{C} \mathrm{m}^{-1}$ following Suga et al. (1997). In analyzing the model solutions, we define the CMW as the low-PV region with $\mathrm{PV}<1.0 \times$ $10^{-10} \mathrm{~m}^{2} \mathrm{~s}^{-1}$ below the mixed layer, a criterion comparable to Suga et al.'s temperature-gradient-based definition. Figure 2 compares the model and observed CMW in a longitude-depth section at $34^{\circ} \mathrm{N}$. The model captures the
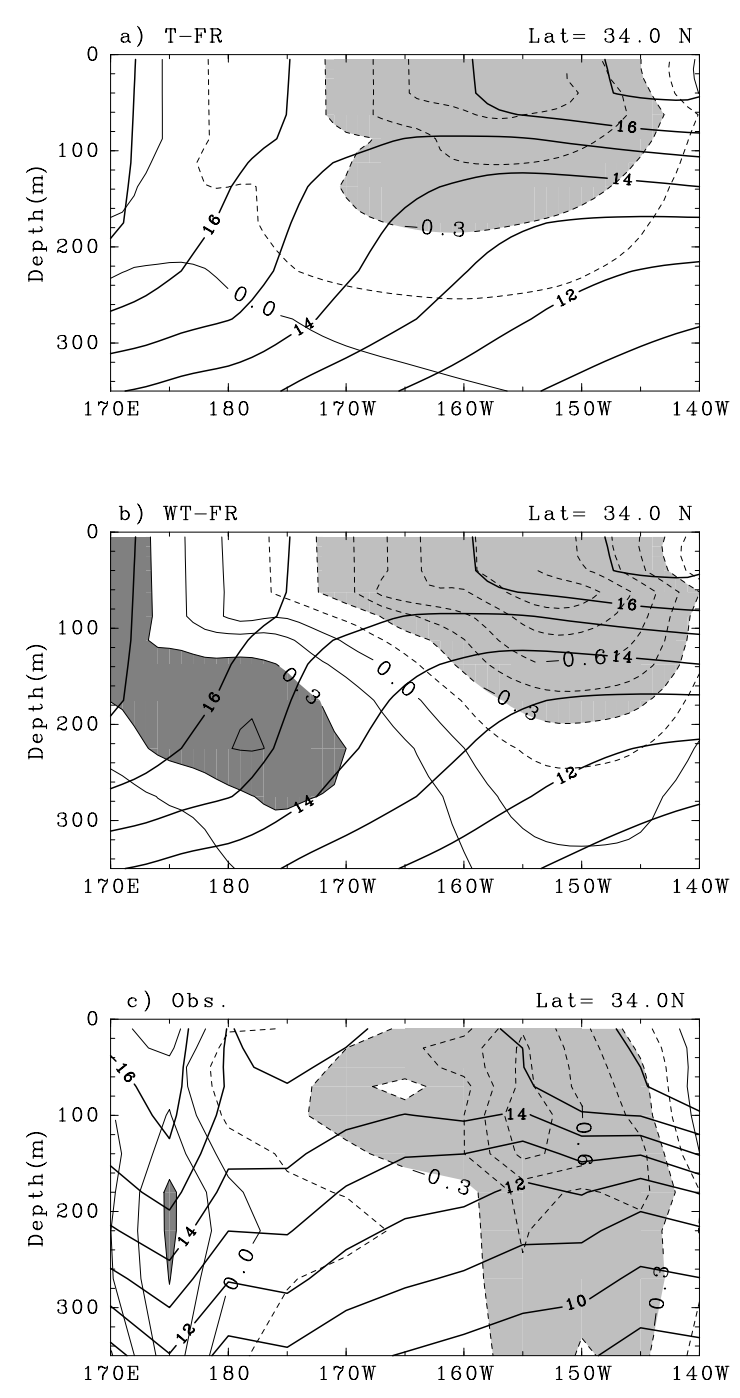

Fig. 4. Decadal temperature difference between 1980-1989 and 1970-1979 in March at $34^{\circ} \mathrm{N}$ in (a) the T-FR run, (b) the WT-FR run, and (c) observations, with dark shade $>0.3^{\circ} \mathrm{C}$ and light shade $<-0.3^{\circ} \mathrm{C}$. Time-mean temperature is plotted in solid thick contours.

low PV water beneath the winter mixed layer east of the dateline. With the $14-16^{\circ} \mathrm{C}$ isothermal becoming almost vertical at $180-170^{\circ} \mathrm{W}$, the CMW's PV signal is stronger in the model than in the XBT data. A strong horizontal temperature gradient is found in and west of the CMW in both the model and observations. The model CMW has a warm bias, occupying a temperature range of $12-16^{\circ} \mathrm{C}$ in comparison with the observed range of $10-13^{\circ} \mathrm{C}$.

\section{Interdecadal Variations}

\subsection{Potential vorticity}

This section concerns interdecadal variations in subsurface temperature. Figure 2 shows the longitude-depth 

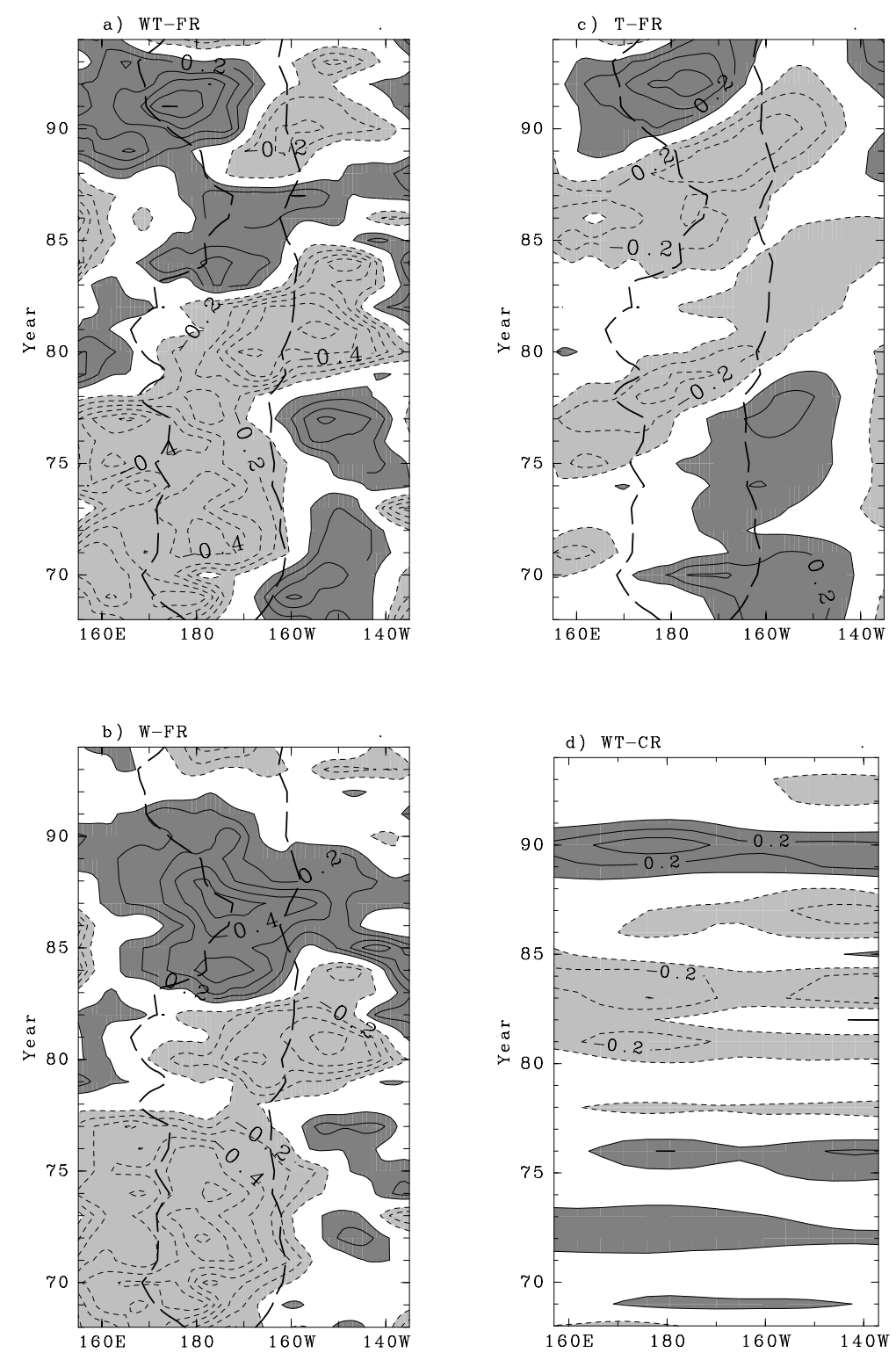

Fig. 5. Longitude-time sections of $175 \mathrm{~m}$ temperature anomalies at $34^{\circ} \mathrm{N}$ in (a) the WT-FR, (b) W-FR, (c) T-FR, and (d) WT-CR runs (dark shade $>0.1^{\circ} \mathrm{C}$ and light shade $<-0.1^{\circ} \mathrm{C}$ ). The dashed contours denote where PV is less than $1.0 \times 10^{-10} \mathrm{~m}^{2} \mathrm{~s}^{-1}$ in each experiments except for $(\mathrm{d})$.

sections at $34^{\circ} \mathrm{N}$ of PV before (long dashed) and after 1979 (shade), in the model and observations. In the model, the CMW moved slightly eastward by $5-10$ degrees in longitude. This eastward shift of the CMW is visible in the observed data, but is less pronounced, partly because of the coarse longitudinal resolution of the XBT data (5 degrees). Xie et al. (2000) investigated the mechanisms for this eastward shift of the CMW in a similar OGCM, albeit without interannual SST forcing. They showed that an eastward shift in the CMW formation region as well as eastward advection on isopycnals by anomalous gyre circulation are responsible for the anomalous shift in the
CMW path. Figure 3 illustrates the former mechanism; the cross point between the $25.8 \sigma_{\theta}$ isoline and the MLD front as represented by the MLD $=150 \mathrm{~m}$ contour, where the model CMW forms, moves eastward after the 1970s climate regime shift.

\subsection{Temperature anomalies}

Figure 4(a) shows the zonal section of the temperature differences after and before the climate regime shift in the T-FR run where only the interannual SST forcing is applied. Consistent with previous studies, a broad cooling signal is subducted into the subsurface, the lower 


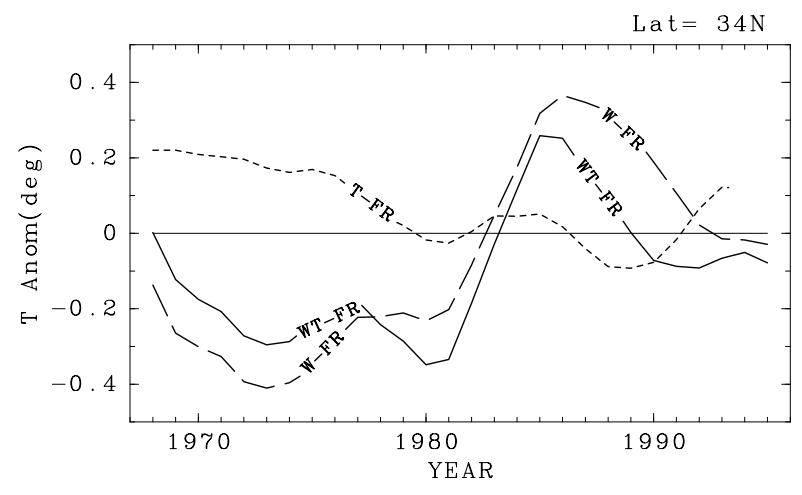

Fig. 6. Temperature anomalies as a function of time on the time-mean $25.8 \sigma_{\theta}$ surface (WT-FR) in the W-FR (long dashed), WT-FR (solid) and T-FR (dashed) runs at $34^{\circ} \mathrm{N}$ $166^{\circ} \mathrm{W}$.

portion of which reaches the CMW region centered at 200 $\mathrm{m}$ from $180^{\circ}$ to $160^{\circ} \mathrm{W}$. This is because the SST cooling after the climate shift is located around the formation region of the CMW (Fig. 3). When the interannual wind forcing is also included (the WT-FR run; Fig. 4(b)), a weak warming instead appears in the CMW around $180^{\circ}$ to $170^{\circ} \mathrm{W}$ and the cooling is greatly increased in the CMW around $160^{\circ} \mathrm{W}$ to $140^{\circ} \mathrm{W}$.

Xie et al. (2000) studied this dynamical warming associated with a CMW forced by interannual changes in wind stress. The presence of the thick CMW pushes up the isopycnals in the upper thermocline. When the CMW moves eastward after the mid-1970s, these pushed-up isopycnals fall down in the western part of the CMW (around $180^{\circ}$ to $170^{\circ} \mathrm{W}$ ) and give rise to a subsurface warming there (figure 5 of Xie et al., 2000). Thus, the temperature anomalies in the WT-FR run can be viewed as a superposition of this dynamical warming with the subducted cooling signal. Otherwise, there is a cooling region in the eastern part of the CMW (around from $160^{\circ} \mathrm{W}$ to $150^{\circ} \mathrm{W}$ ). A comparison of Figs. 4(a) and (b) suggests that this is mainly caused by a subducted cold SST signal. A similar temperature anomaly pattern can be seen to some extent in observations (Fig. 4(c)), where the strongest cooling takes place east of and above the CMW while temperature anomalies-either positive or negative-are small in the western part of the CMW.

Figure 5 shows the longitude-time sections of $175 \mathrm{~m}$ temperature anomalies at $34^{\circ} \mathrm{N}$, in the WT-FR (a), W-FR (b) and T-FR (c) runs. Anomalies are caused by dynamical processes in panel (b), thermodynamical processes (SST) in (c), and their combined effects in (a). In the CMW that time-varying position is marked by the dashed contours in each run; there is a small warming after the early 1980s in Fig. 5(a), which is also seen in the decadal difference map of Fig. 4(b) for the climate regime shift.
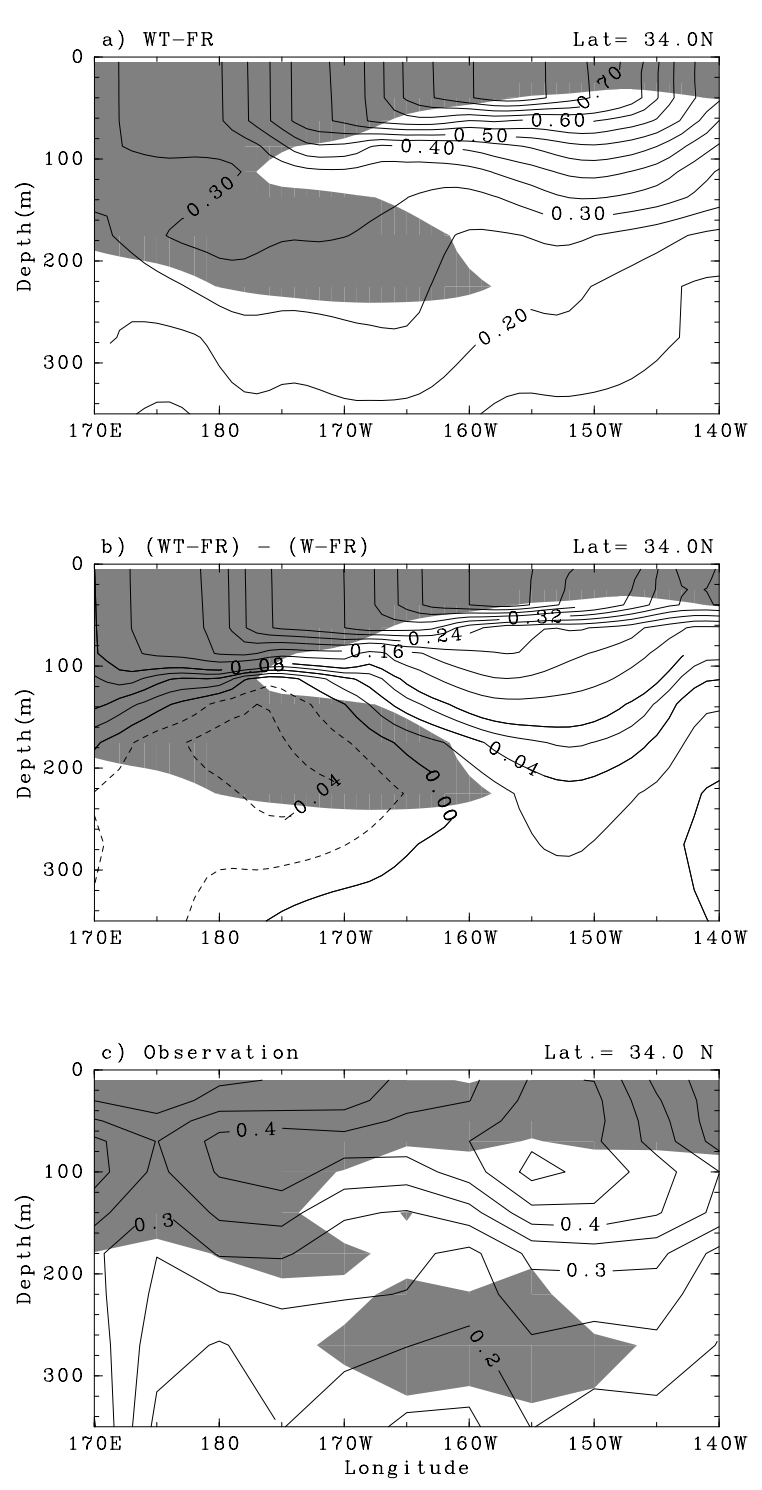

Fig. 7. (a) Standard deviation of March temperature anomalies for 40 years in the WT-FR run at $34^{\circ} \mathrm{N}$. Contour intervals are $0.05^{\circ} \mathrm{C}$. (b) Difference of standard deviation of March temperature anomalies for 40 years between the WT-FR and $\mathrm{W}$-FR at $34^{\circ} \mathrm{N}$. Contour intervals are $0.02^{\circ} \mathrm{C}(<0.08)$ and $0.04^{\circ} \mathrm{C}(>0.08)$. (c) Observed standard deviation of March temperature anomalies for 1958 to 1997 at $34^{\circ} \mathrm{N}$. Contour interval is $0.05^{\circ} \mathrm{C}$. Shaded areas denote the CMW where $\mathrm{PV}<1.0 \times 10^{-10} \mathrm{~m}^{2} \mathrm{~s}^{-1}$ in (a) and (b) and $(-(\partial T) /(\partial z))<$ $0.015^{\circ} \mathrm{C} \mathrm{m}^{-1}$ in (c).

This warming signal lags several years behind the climate regime shift when large surface wind changes occur, a delay due to the spin up of the subtropical gyre and its anomalous advection of the CMW (Xie et al., 2000). This warming signal is much stronger in the W-FR run (Fig. 5(b)), again indicating that it is part of the dynamical response to wind stress forcing. The thermodynami- 

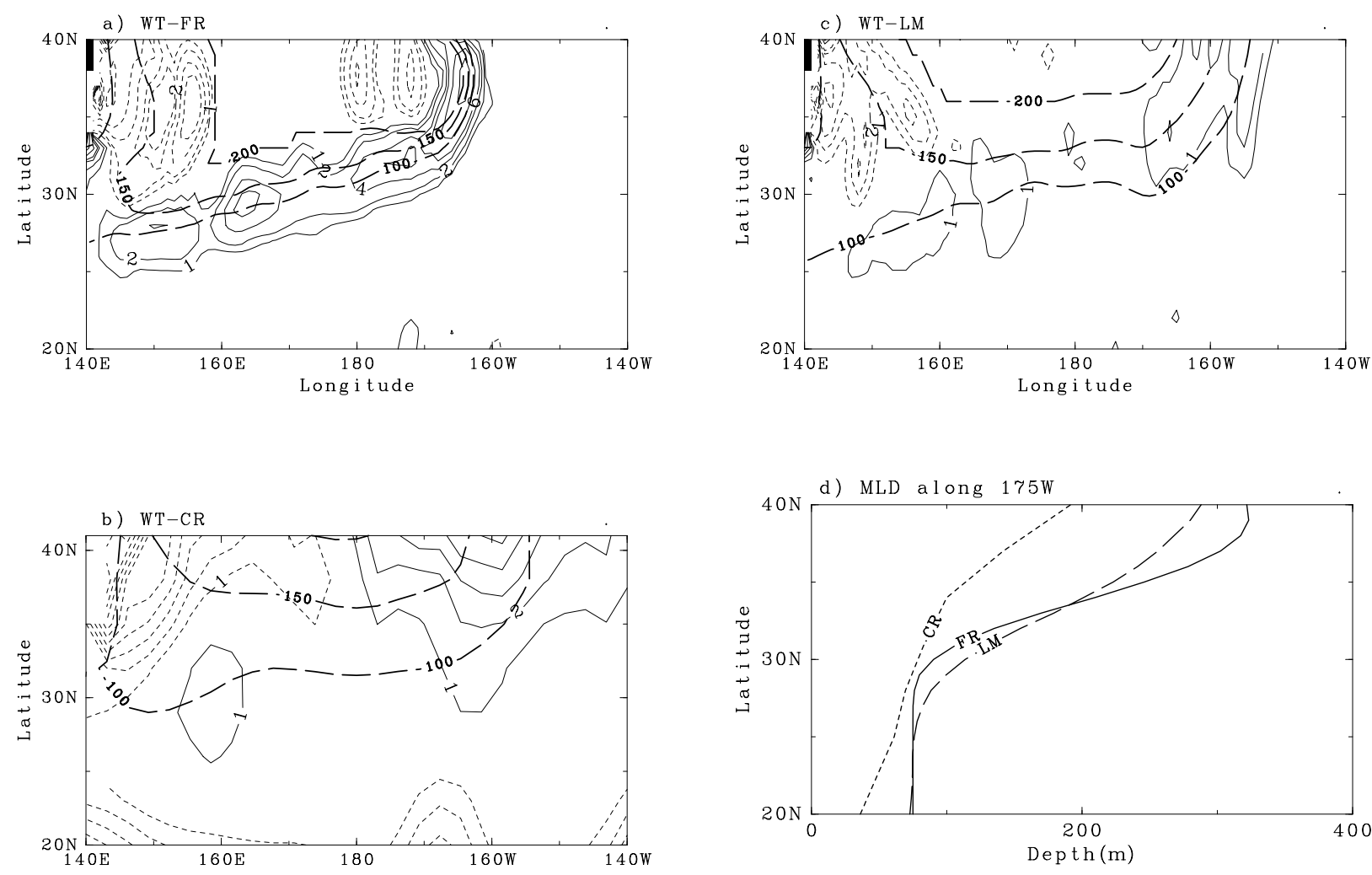

Fig. 8. Lateral induction at the bottom of the mixed layer (zero contours are omitted) and MLD (only the 100, $150,200 \mathrm{~m}$ contours shown) in (a) the WT-FR, (b) WT-CR and (c) WT-LM runs in March 1997. For lateral induction, contour intervals are $2.0 \times 10^{-4} \mathrm{~m} \mathrm{~s}^{-1}$ (added $\pm 1.0 \times 10^{-4} \mathrm{~m} \mathrm{~s}^{-1}$ lines) in (a), $1.0 \times 10^{-4} \mathrm{~m} \mathrm{~s}^{-1}$ in (b) and (c). Meridional sections of the MLD along $175^{\circ} \mathrm{W}$ in the WT-FR (FR; solid), WT-CR (CR; dotted) and WT-LM (LM; long dashed) runs are shown in (d).

cal response in Fig. 5(c) features cooling after the mid1970 s in a region including the CMW, consistent with previous studies (e.g. Nonaka et al., 2000) (see also Fig. 4(a)). Temperature differences between WT-FR and WFR runs (not shown) are very similar to those in Fig. 5(c), suggesting that the model response to the SST forcing is quite linear.

As another way to illustrate these effects of the wind stress and SST forcing, we show in Fig. 6 the time series of temperature anomalies at the core of the CMW on its time-mean isopycnal surface $25.8 \sigma_{\theta}$, at $34^{\circ} \mathrm{N}$. In the CMW, the dynamical and thermodynamical responses generally have opposite signs, except around 1980 and 1990 when they reinforce each other. As a result, adding the SST forcing to the model leads to a reduction in temperature variability within the CMW.

\subsection{Standard deviation distribution}

Figures 7(a) and (b) show standard deviation of temperature anomaly in the WT-FR run and standard deviation difference between the WT-FR and the W-FR runs for 40 years. Figure 7(c) shows the observed standard deviation of temperature. To remove higher-frequency interannual variations, a 5-year running mean is first applied. A large standard deviation is seen in the nupper layer but tends to become small in the lower layer including the CMW in the WT-FR (Fig. 7(a)) and observation (Fig. 7(c)). The subduction of SST variations substantially increases the subsurface variability in the upper thermocline (Fig. 7(b)). But because this thermodynamical response opposes the wind stress-induced dynamical response in the CMW, temperature variability there is reduced. Thus, the CMW plays a special role in the response of the subtropical gyre to atmospheric changes and may be a region of small temperature variability when both the wind stress and SST forcing are present. While this observational evidence is inconclusive, our model results suggest that the CMW dynamics, which generally oppose the thermodynamical response to the SST forcing, are responsible for the reduced temperature variability in the CMW.

\section{Sensitivity to Model Resolutions}

Together with previous studies (Inui et al., 1999; Xie et al., 2000), the above results demonstrate that the anomalous movement of the CMW as a thick layer of rela- 

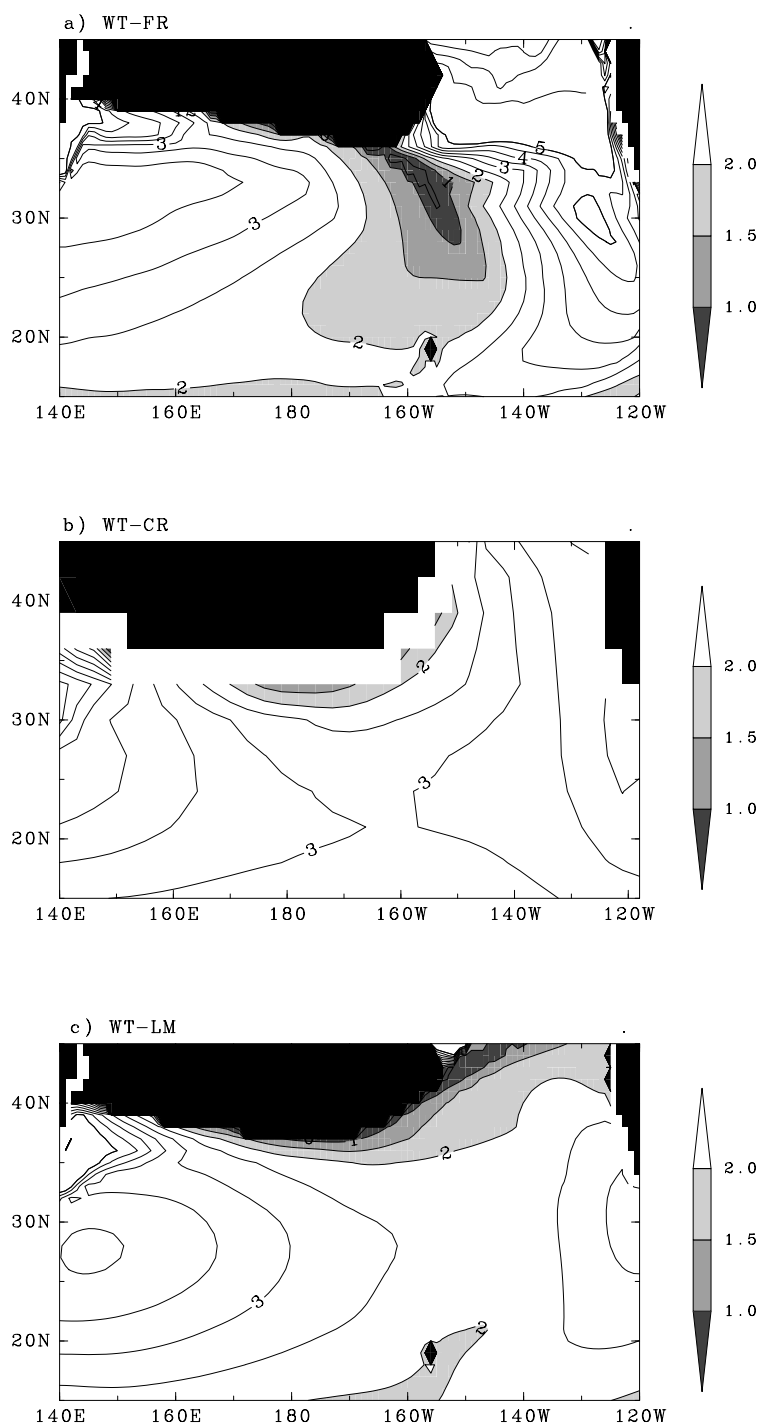

Fig. 9. $\mathrm{PV}\left(\times 10^{-10} \mathrm{~m}^{2} \mathrm{~s}^{-1}\right)$ on the $25.8 \sigma_{\theta}$ isopycnal in (a) the WT-FR, (b) WT-CR and (c) WT-LM runs in March 1997. Shade denotes where PV is less than $2.0 \times 10^{-10} \mathrm{~m}^{2} \mathrm{~s}^{-1}$, and the outcroped and land areas are blacked out.

tively uniform water is a potentially important mechanism for subsurface temperature variability. Its low PV gives the CMW a unique role in the ocean's dynamical adjustment. As Williams (1991) and Kubokawa (1999) show, the PV $\left(q_{m}\right)$ of a water mass at the time of subduction is determined by

$$
q_{m}=\frac{f}{\bar{\rho}} \cdot \frac{\boldsymbol{u} \cdot \nabla \rho}{(\boldsymbol{u} \cdot \nabla h)+w},
$$

where $f$ is the Coriolis parameter, $\rho$ is the seawater density, $\bar{\rho}$ is a reference density value, $h$ is the depth of the mixed layer, $w$ is the vertical velocity, and $\boldsymbol{u}$ is the hori-
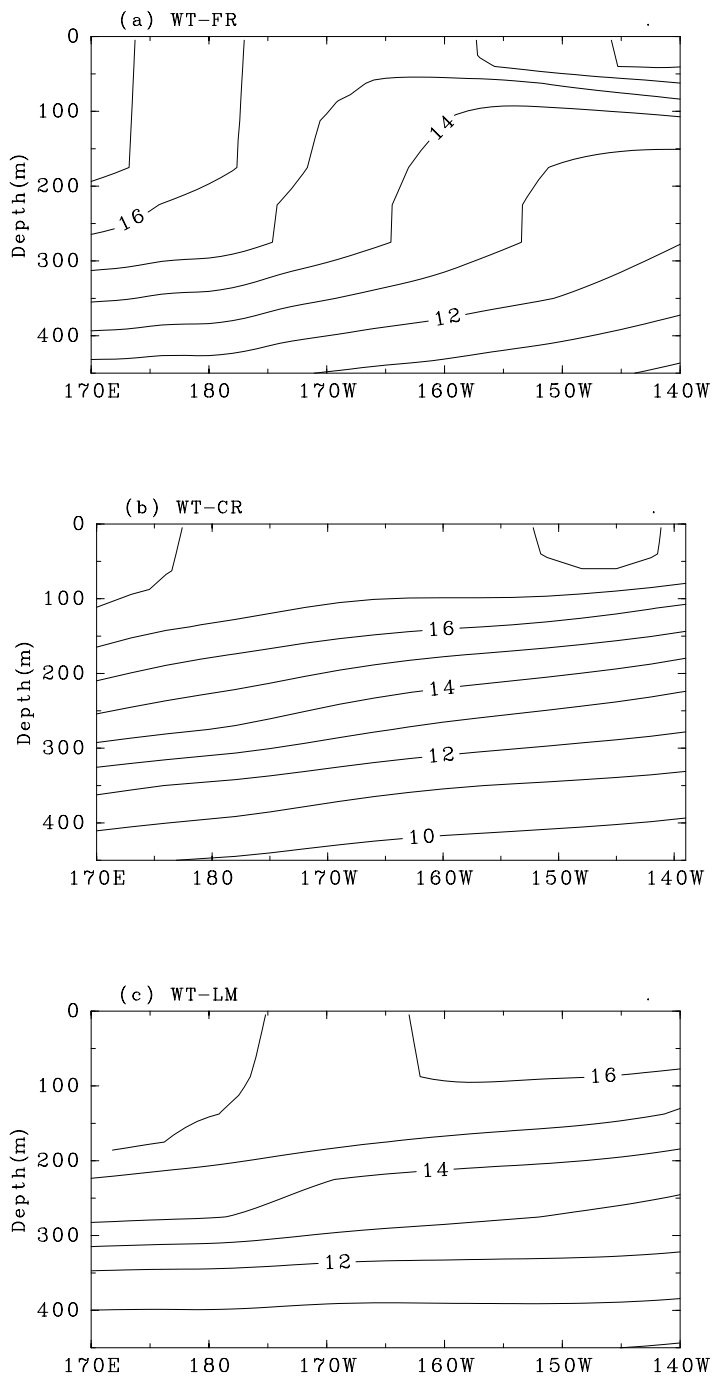

Fig. 10. March zonal section of temperature at $33^{\circ} \mathrm{N}$ in the (a) WT-FR, (b) WT-CR and (c) WT-LM runs in March 1997. Contour intervals are $1^{\circ} \mathrm{C}$.

zontal current velocity at the bottom of the mixed layer. Hosoda et al. (2001) did a term-by-term analysis of this diagnostic equation for the North Pacific subtropical gyre and separated temperature and salinity effects. In the CMW formation region, the MLD gradient is most important for its low PV formation. It is conceivable that this MLD gradient decreases in coarse-resolution models, and so does the CMW's PV.

To demonstrate this sensitivity to model resolution, we carried out another experiment with the same OGCM but at a $3 \times 3$ degrees resolution (the $\mathrm{CR}$ run). Larger mixing coefficients are necessary to ensure computational stability (Table 1). To isolate the effects of increased mixing coefficients, we carried out one more experiment with the increased mixing coefficients as in the CR run but at the $1 \times 1$ degree resolution (the LM run). The vertical 
resolution and other model parameters are all kept the same as in the FR run.

In the CMW formation, the subduction rate is dominated by lateral induction, a process by which surface water is subducted into the main thermocline across the sloping mixed layer bottom (e.g. Williams, 1991; Marshall et al., 1993). The first term of the denominator in Eq. (1) is a measure of lateral induction (the second term is related to Ekman pumping). We have computed the lateral induction rate at the bottom of mixed layer,

$$
\boldsymbol{u} \cdot \nabla h=u \frac{\partial h}{\partial x}+v \frac{\partial h}{\partial y}
$$

which is a product of subducting horizontal velocity and MLD gradient (Qu et al., 2002). Figures 8(a)-(c) shows the distributions of this lateral induction rate along with MLD. Strong lateral induction is found in the FR run along the MLD front. In both the CR and LM runs, the lateral induction rate is substantially reduced as a result of both weakened MLD front (Fig. 8(d)) and slowed eastward current.

This reduced lateral induction leads to a marked increase in the PV in CMW's formation region (Fig. 9). Moreover, the low-PV tongue that extends southward becomes much weaker in the CR and LM runs than in the FR run; the low PVs are strongly trapped near the outcrop line and dissipate rapidly as the subducted water moves southward. This loss of low-PV character leads to large changes in the vertical stratification of temperature (Fig. 10). In contrast to the well-defined thick layer of the CMW in the WT-FR run (Fig. 10(a)), the temperature stratification becomes quite uniform underneath the winter mixed layer in the WT-CR run (Fig. 10(b)). In the WTLM run, a weak mode water is found only within a small area between the $13^{\circ} \mathrm{C}$ and $14^{\circ} \mathrm{C}$ isothermals (Fig. $10(\mathrm{c})$ ).

The changes in temperature stratification in the coarser-resolution WT-CR run lead to a model response to combined wind and SST forcing that is very different from that in the finer-resolution WT-FR run. At $175 \mathrm{~m}$, without the CMW, the anomaly pattern in the coarserresolution model (WT-CR run; Fig. 5(d)) is nearly zonally uniform, featuring a cooling around 1977 . The coarseresolution model's response to the combined wind and SST forcing is somewhat similar to the fine-resolution model's response to the SST forcing only, a reasonable result given the absence of the mode water dynamics in the CR run.

The sensitivity of the model anomalies to resolution is not limited to the upper thermocline. Figure 11 contrasts temperature anomalies associated with the mid1970s climate regime shift at $350 \mathrm{~m}$ between the fine and coarse resolution models and compare them with observations at $400 \mathrm{~m}$. The WT-FR run successfully reproduces
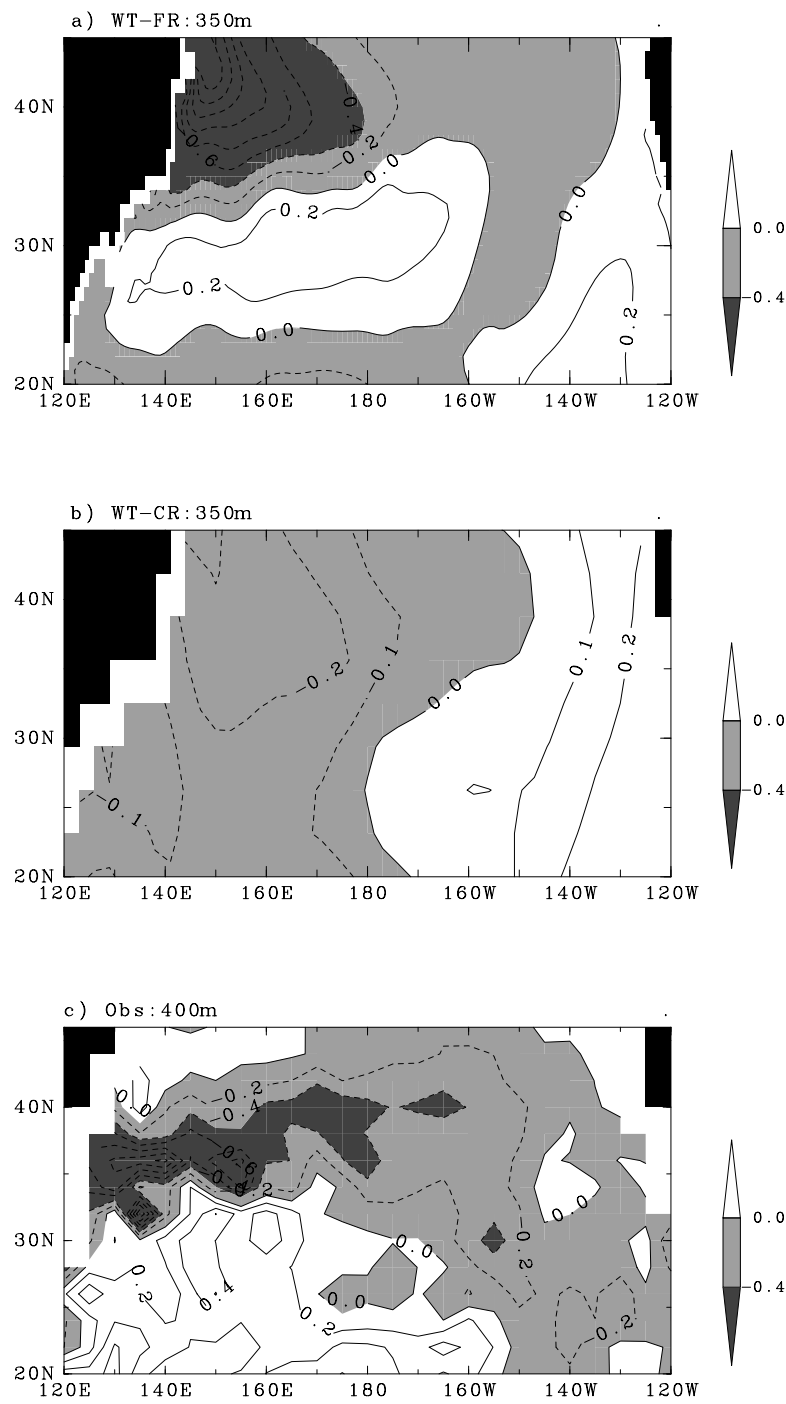

Fig. 11. March temperature differences between averaged 1980-86 and 1970-76 at $350 \mathrm{~m}$ in (a) the WT-FR and (b) WT-CR runs, and (c) in observations. Contour intervals are $0.2^{\circ} \mathrm{C}$ in (a) and (c) and $0.1^{\circ} \mathrm{C}$ in (b), respectively. Light and dark shades denote where anomalies are less than $0.0^{\circ} \mathrm{C}$ and $-0.4^{\circ} \mathrm{C}$, respectively.

some key features of the observed anomaly pattern, including a cooling north of $32^{\circ} \mathrm{N}$ and a warming to the south. In both the WT-FR run and observations, the northern cooling is zonally oriented and tends to intensify to the west, features indicative of the adjustment via Rossby waves of the first baroclinic mode (Miller et al., 1998; Deser et al., 1999). The maximum warming in the southern subtropical gyre tilts southwestward in the WT-FR run, which we interpret as indicative of the dynamical warming in the western part of the CMW in response to the wind stress forcing that has been discussed in Section 3, while Deser et al. (1999) suggest that the spinning-up 
of the subtropical gyre after the mid-1970s causes a westward extending subsurface warming.

In the WT-CR run, the anomalies are generally much reduced in magnitude. Without the mode water dynamics, the southern warming disappears altogether west of the international dateline. The northern cooling is also weakened because of weakened Kuroshio Extension current.

\section{Summary and Discussion}

We have investigated interdecadal variations in the North Pacific subsurface temperature using an OGCM, focusing on the decadal differences before and after the mid-1970s climate regime shift when the atmospheric Aleutian low strengthened, leading to large changes in surface wind stress and SST over the North Pacific. We carried out a set of experiments to isolate the wind stress and SST forcing and study their collective effects on subsurface variability. In the T-FR run with SST as the only interannual forcing, the upper thermocline experiences a cooling as the negative SST anomalies are subducted and spread widely after the climate regime shift, a thermodynamical response consistent with previous studies (Deser et al., 1996; Scheider et al., 1999; Nonaka et al., 2000). The results from the W-FR run, where only the wind stress forcing varies from one year to another, confirm the potential importance of the CMW in the dynamical adjustment of the subtropical gyre. Specifically, the thick layer of the CMW is found to move eastward after the climate regime shift in response to the changes in wind stress forcing, giving rise to a subsurface warming in the western part of the CMW. In the WT-FR run where both interannual variations in wind stress and SST are applied in the model, after the climate regime shift, the CMW forms with colder SSTs and follows an anomalously eastward path after being subducted in the thermocline. The resultant dynamical warming and thermodynamical cooling act to oppose each other, reducing temperature variability in the CMW, though there is some eddy-like variability in our 1 degree model, especially in the Kuroshio Extension and the return flow region near Japan. But the formation region of the CMW is further to the east away from this region of eddies, therefore we consider that they have little influence on interannual-decadal variability.

We have compared the model simulation with historical XBT measurements and obtained some evidence for reduced temperature variability in the observed CMW. Observations also suggest a similar eastward shift of the CMW location after the mid-1970s, but their poor sampling and horizontal resolution render this observational evidence inconclusive. The model response in the lower thermocline (upper $350 \mathrm{~m}$ ) in the WT-FR run agrees well with observations. In particular, a warming that extends in a southwestward direction in the southern part of the subtropical gyre after the climate regime shift appears consistent with our interpretation based on the mode-water dynamics.

The low PV signature of the CMW is a result of sharp MLD gradient and enhanced lateral induction in the KOE region. In a coarse resolution model, the MLD front weakens substantially and the PV minimum on the CMW isopycnal becomes unclear, resulting in significant changes in vertical stratification of temperature. The weakening or disappearance of this low-PV water in the background stratification rids the model of the modewater dynamics described above. The resultant response to combined wind and SST forcing looks substantially different from that in the finer resolution model, despite the fact that all the parameters are kept the same (except a numerically necessary increase in horizontal mixing coefficients). Many of previous OGCM and coupled GCM simulations were carried out at horizontal resolutions of 2 degrees or coarser. While some part of lack of the subsurface variability (southern warming, for example) may be due to inaccurate wind and thermal forcing in their OGCM experiments, the sensitivity of subsurface ocean response to changes in resolution suggests caution in interpreting the results from those coarser resolution models.

The results from our sensitivity experiments raise a question: what happens if we further increase the model resolution above 1 degree ? Qu et al. (2002) have analyzed a 1/4 degree simulation of a similar OGCM and found a low-PV tongue similar to that in our 1 degree model (Fig. $8(a))$ that extends southward from the mode water formation regions near the KOE. While increased resolution allows the model to resolve an even sharper MLD front, energetic meso-scale eddies due to shear instabilities act to weaken the MLD gradient. A major eddy effect that Qu et al. (2002) identify in their analysis is the formation of a double Kuroshio-Oyashio jet structure in their eddy-resolving model (in our 1 degree model, the "KOE" is a broad eastward current $1000 \mathrm{~km}$ wide). They suggest that this double jet structure leads to two localized maxima in subduction rate that correspond to the separate subtropical mode water and CMW.

The low-PV mode waters are an overlooked feature in studies of subtropical gyre dynamics. Along with several recent studies (Kubokawa, 1999; Inui et al., 1999; Xie et al., 2000), this study shows that its low-PV nature gives the CMW an important role to play in ocean adjustment, which may lead to localized temperature anomalies along the path of the CMW. The model response to the atmospheric changes around the mid-1970s differs a great deal with and without this mode-water dynamics (compare Figs. 5(a) and (d), Figs. 11(a) and (b)). Compared with observations, the low-PV signature of the model CMW in our 1 degree model is probably too strong, 
a statement that holds true even if we consider the fact that observational grid data are subject to heavy spatial smoothing. A realistic simulation of the mode waters in the subtropical gyre remains a challenge for ocean modeling, requiring a realistic simulation of their subduction rates that in turn requires the model to reproduce both the circulation and MLD distribution. This is a challenge that needs to be met, given the potential importance of the mode water dynamics that this and other studies have suggested. Critical examination of PV distributions on isopycnals and comparison with reliable observations are the first step toward a solution.

\section{Acknowledgements}

We thank A. Kubokawa and T. Suga for helpful discussions. The computations were performed at Hokkaido University Computing Center, with partial support from University of Tokyo's Center for Climate System Research. IPRC publication \#251 and SOEST publication \#6308. The IPRC is partially supported by the Frontier Research System for Global Change. The figures were produced by the GFD-DENNOU library.

\section{References}

Cayan, R. C. (1992): Latent and sensible heat flux anomalies over the Northern Oceans: Driving the sea surface temperature. J. Phys. Oceanogr., 22, 859-881.

Cox, M. D. (1987): Isopycnal diffusion in a z-coordinate ocean model. Ocean Modeling, 74, 1-5.

Deser, C., M. A. Alexander and M. S. Timlin (1996): Upperocean thermal variations in the North Pacific during 19701991. J. Climate, 9, 1840-1855.

Deser, C., M. A. Alexander and M. S. Timlin (1999): Evidence for a Wind-Driven Intensification of the Kuroshio Current Extension from the 1970 s to the 1980 s. J. Climate, 12, 16971706.

Gu, D. and S. G. H. Philander (1997): Internal climate fluctuations that depend on exchanges between the tropics and extratropics. Science, 275, 805-807.

Hosoda, S., S.-P. Xie, K. Takeuchi and M. Nonaka (2001): Eastern North Pacific Subtropical Mode Water in a GCM: Formation mechanism and salinity effects. J. Geophys. Res., 106, 19671-19681.

Inui, T., K. Takeuchi and K. Hanawa (1999): A numerical investigation of the subduction process in response to an abrupt intensification of westerlies. J. Phys. Oceanogr., 29, 1993-2015.

Kalnay, E., M. Kanamitsu, R. Kistler, W. Collins, D. Deaven, L. Gandin, M. Iredell, S. Saha, G. White, J. Woollen, Y. Zhu, A. Leetmaa, R. Reynolds, M. Chelliah, W. Ebisuzaki, W. Higgins, J. Janowiak, K. C. Mo, C. Ropelewski and J. Wang (1996): The NCEP/NCAR 40-Year Reanalysis Project. Bull. Amer. Meteor. Soc.

Kubokawa, A. (1999): Ventilated thermocline strongly affected by a deep mixed layer: A theory for subtropical countercurrent. J. Phys. Oceanogr., 29, 1314-1333.

Kubokawa, A. and T. Inui (1999): Subtropical countercurrent in an idealized ocean GCM. J. Phys. Oceanogr., 29, 13031313.

Kubokawa, A. and S.-P. Xie (2002): Steady response of a ventilated thermocline to enhanced Ekman pumping. $J$. Oceanogr., 58, 565-575.

Latif, M. and T. P. Barnett (1994): Causes of decadal climate variability over the North Pacific and North America. Science, 266, 634-637.

Levitus, S. and T. P. Boyer (1994): World Ocean Atlas 1994, Vol. 4, Temperature. NOAA Atlas NESDIS 3, U.S. Dept. of Commerce, Washington, D.C., 117 pp.

Levitus, S. R. Burgett and T. P. Boyer (1994): World Ocean Atlas 1994, Vol. 3, Salinity. NOAA Atlas NESDIS 3, U.S. Dept. of Commerce, Washington, D.C., 97 pp.

Liu, Z. (1999): Forced planetary wave response in a thermocline gyre. J. Phys. Oceanogr., 29, 1036-1055.

Mantua, N. J., S. R. Hare, Y. Zhang, J. M. Wallace and R. C. Francis (1997): A Pacific interdecadal climate oscillation with impacts on salmon production. Bull. Amer. Meteor. Soc., 78, 1069-1079.

Marshall, J. C., A. J. G. Nurser and R. G. Williams (1993): Inferring the subduction rate and period over the North Atlantic. J. Phys. Oceanogr., 23, 1315-1329.

Miller, A. J., D. R. Cayan and W. B. White (1998): A westward-intensified decadal change in the North Pacific Thermocline and gyre-scale circulation. J. Climate, 11, 3112-3127.

Minobe, S. (1997): A 50-70-year climatic oscillation over the North Pacific and North America. Geophys. Res. Lett., 24, 683-686.

Nakamura, H. (1996): A pycnostad on bottom of the ventilated portion in the central subtropical circulation using an eddyresolving quasi-geostrophic model. J. Oceanogr., 52, 171188 .

Nitta, T. and S. Yamada (1989): Recent warming of sea surface temperature and its relationship to the Northern Hemisphere circulation. J. Meteor. Soc. Japan, 67, 375-382.

Nonaka, M. and S.-P. Xie (2000): Propagation of North Pacific interdecadal subsurface temperature anomalies in an ocean GCM. Geophys. Res. Lett., 27, 3747-3750.

Nonaka, M., S.-P. Xie and K. Takeuchi (2000): Equatorward spreading of a passive tracer with application to North Pacific interdecadal temperature variations. J. Oceanogr., 56, 173-183.

Pacanowski, R. C., K. W. Dixon and A. Rossati (1991): The GFDL Modular Ocean Model User Guide. GFDL Ocean Group Tech. Rep., No. 2.

Qiu, B. (2000): Interannual variability of the Kuroshio extension system and its impact on the wintertime SST field. $J$. Phys. Oceanogr., 30, 1486-1502.

Qu, T., S.-P. Xie, H. Mitsudera and A. Ishida (2002): Subduction of the North Pacific Mode Waters in a Global HighResolution GCM. J. Phys. Oceanogr., 32, 746-763.

Reynolds, R. W. and T. M. Smith (1994): Improved global sea surface temperature analyses using optimal interpolation. J. Climate, 7, 929-948.

Schneider, N. and A. Miller (2001): Predicting western North Pacific ocean climate. J. Climate, 14, 3997-4002.

Schneider, N. S., S. Venzke, A. J. Miller, D. W. Pierce, T. P. 
Barnett, C. Deser and M. Latif (1999): Pacific thermocline bridge revisited. Geophys. Res. Lett., 26, 1329-1332.

Schneider, N., A. J. Miller and D. W. Pierce (2002): Anatony of North Pacific decadal variability. J. Climate, 15, 586-605.

Seager, R., K. Kushnir, N. H. Naik, M. A. Cane and J. Miller (2001): Wind-driven shifts in the latitude of the KuroshioOyashio Extension and generation of SST anomalies on decadal timeseries. J. Climate, 14, 4249-4265.

Suga, T., Y. Takei and K. Hanawa (1997): Thermostad distribution in the North Pacific subtropical gyre: The Central Mode Water and the Subtropical Mode Water. J. Phys. Oceanogr., 27, 140-152.

Tanimoto, Y., N. Iwasaka, K. Hanawa and Y. Toba (1993): Characteristic variations of sea surface temperature with multiple time scales in the North Pacific. J. Climate, 6, 11531160.

Tomita, T., S.-P. Xie and M. Nonaka (2002): Estimates of surface and subsurface forcing for decadal sea surface temperature variability in the mid-latitude North Pacific. $J$. Meteor. Soc. Japan, 80, 1289-1300.

White, W. B. (1995): Design of a global observing system for gyre-scale upper ocean temperature variability. Prog.
Oceanogr., 36, 169-217.

Williams, R. G. (1991): The role of the mixed layer in setting the potential vorticity of the main thermocline. J. Phys. Oceanogr., 21, 1803-1814.

Xie, S.-P., T. Kunitani, A. Kubokawa, M. Nonaka and S. Hosoda (2000): Interdecadal thermocline variability in the North Pacific for 1958-1997: A GCM simulation. J. Phys. Oceanogr., 30, 2798-2813.

Yasuda, I., H. Sugisaki, Y. Watanabe, S. Minobe and Y. Oozeki (1999): Interdecadal variations in Japanese sardine and ocean/climate. Fish. Oceanogr., 8, 18-24.

Yasuda, T. and K. Hanawa (1997): Decadal changes in the mode waters in the midlatitude North Pacific. J. Phys. Oceanogr., 27, 858-870.

Yasuda, T. and Y. Kitamura (2003): Long-term variability of North Pacific Subtropical Mode Water in response to spinup of the subtropical gyre. J. Oceanogr., 59, 279-290.

Zhang, R. H., L. M. Rothstein and A. J. Busalacchi (1998): Origin of upper-ocean warming and El Niño change on decadal scale in the tropical Pacific Ocean. Nature, 391, 879-883. 